\title{
PENERAPAN METODE QUALITY FUNCTION DEPLOYMENT (QFD) UNTUK PENGEMBANGAN DESAIN MOTIF BATIK KHAS KALIMANTAN TIMUR
}

\author{
Mafazah Noviana, Sujoko Hastanto *) \\ Jurusan Desain Politeknik Negeri Samarinda \\ Jl. Ciptomangunkusumo Samarinda, Kalimantan Timur
}

\begin{abstract}
Abstrak
Seni membatik di atas kain dengan corak yang khas dari setiap daerah di Indonesia hampir tenggelam ditelan perkembangan jaman. Padahal, seni membatik merupakan kearifan lokal masyarakat Indonesia yang mencerminkan penghargaan terhadap alam dan disuguhkan dengan dorongan penuh atas kecintaan dan apresiasi tinggi

Tujuan dari penelitian adalah mengembangkan desain motif-motif batik khas Kalimantan Timur yang akan memperkaya khasanah budaya batik Kalimantan Timur, disesuaikan dengan selera atau keinginan konsumen; meningkatkan minat khususnya masyarakat Kalimantan Timur dan umumnya masyarakat Indonesia untuk menggunakan batik sebagai identitas kultural suku bangsa Indonesia; dan meningkatkan potensi pengembangan desain motif-motif batik khas Kalimantan Timur dengan mengaplikasikannya pada produk-produk.

Metode yang digunakan pada penelitian ini adalah metode Quality Function Deployment (QFD) untuk pengembangan desain motif batik khas Kalimantan Timur. Objek yang diteliti adalah batik khas Kalimantan Timur. Dengan menganalisis motif-motif batik khas Kalimantan Timur yang sesuai dengan keinginan pasar guna pengembangan produk.

Hasil akhir dari penelitian ini diharapkan dapat menghasilkan pengembangan desain-desain baru motif batik khas Kalimantan Timur yang dapat diaplikasikan pada produk-produk kebutuhan masyarakat sehari-hari yang menunjang identitas kultural suku bangsa, seperti busana (seragam dinas dan sekolah), asesoris, souvenir.
\end{abstract}

Kata kunci: QFD; pengembangan; motif; batik; kalimantan timur

\begin{abstract}
Development of batik design is one of effort to strengthening identity and advantage of Indonesia creative industry and also to preserving batik as cultural nation heritage. The purpose of the research is to develop batik motif design East Kalimantan that will enrich culture of East Kalimantan batik.adapted by appetite or desire of consume,. increasing interest especially people of East Kalimantan and the Indonesian people in general to use batik as an Indonesian cultural identity of ethnic groups, and increasing the potency for the development of batik motifs design typical of East Kalimantan by applying the products .This research use Quality Function Deployment (QFD) method to development batik motif design typical East Kalimantan. By analyzing the batik motifs typical East Kalimantan conform with the market demands for product development. The result of this research is development of new batik motif design typical East Kalimantan can be applied to the products of the daily people needs who support the cultural identity of ethnic groups, such as clothing (uniforms), accessories, souvenirs.
\end{abstract}

Keywords: QFD; development; motif; batik; east kalimantan

\section{Pendahuluan}

Pengembangan desain motif batik merupakan salah satu upaya untuk memperkuat identitas dan keunggulan industry kreatif Indonesia sekaligus untuk melestarikan batik sebagai warisan budaya bangsa. Seni membatik di atas kain dengan corak yang khas dari setiap daerah di Indonesia hampir

\footnotetext{
${ }^{*}$ Penulis Korespondensi. E-mail: mafazah79@gmail.com,joko_kpc@yahoo.com
}

tenggelam ditelan perkembangan jaman. Padahal, seni membatik merupakan kearifan lokal masyarakat Indonesia yang mencerminkan penghargaan terhadap alam. Batik memang identik dengan budaya Jawa. Namun, pada kenyataannya terdapat ragam corak unik batik yang berasal dari berbagai penjuru Nusantara, contohnya seperti di daerah Madura, Bali, Seni membatik di atas kain dengan corak yang khas dari setiap daerah di Indonesia hampir tenggelam 
ditelan perkembangan jaman. Padahal, seni membatik merupakan kearifan lokal masyarakat Indonesia yang mencerminkan penghargaan terhadap alam. Batik memang identik dengan budaya jawa. Namun, pada kenyataannya terdapat ragam corak unik batik yang berasal dari berbagai penjuru Nusantara, contohnya seperti di daerah Madura, Bali, Sumatera Barat, Kalimantan Timur dan Toraja. Batik Indonesia tersebut mengandung nilai sejarah dan budaya yang tidak terbatas pada keindahan penampilan yang terbentuk dari komposisi motif dan warna yang serasi, tetapi juga memiliki keindahan spiritual yang hadir melalui ragam hias dan penyusunan pola yang sarat dengan makna filosofis di dalamnya. Tak dapat dipungkiri, Indonesia memang patut berbangga hati telah menyumbangkan konsep "batik" sebagai terminology dalam khazanah tekstil dunia yang kini penggunaannya begitu menyebar, membentang mulai dari Afrika hingga Cina. Namun, sungguh ironis melihat pewaris seni budaya batik Indonesia sendiri jumlahnya masih begitu sedikit. Padahal seni budaya batik disuguhkan dengan dorongan penuh atas kecintaan dan apresiasi tinggi. Oleh karena itu melalui penelitian ini penulis ingin mengembangkan desain motif batik khas Kalimantan Timur yang nantinya akan diterapkan dalam keseharian, khususnya masyarakat Kalimantan Timur dan umumnya masyarakat Indonesia, untuk menunjang identitas kultural suku bangsa Indonesia melalui aplikasi dalam kehidupan sehari-hari.

\section{Tinjauan Pustaka}

Batik mengacu pada 2 (dua) hal. Yang pertama adalah teknik pewarnaan kain dengan menggunakan malam untuk mencegah pewarnaan sebagian dari kain. Dalam literature internasional, teknik ini dikenal dengan wax-resist dyeing. Yang kedua adalah kain atau busana yang dibuat dengan teknik tersebut, termasuk penggunaan motif-motif tertentu yang memiliki kekhasan (Utomo, 2009).

Baroto Tavip, penelitiannya yang berjudul Development Of Indonesia New Batik Design By Exploration And Exploitation Of Recent Context menyatakan Desain batik yang dikembangkan secara garis besar dapat diwujudkan dengan dua metode penggambaran:

1. Penggambaran stilasi harafiah, yaitu visualisasi tema secara langsung dari obyek yang mewakili dan dikembangkan secara stilasi grafis yang sesuai.

2. Penggambaran visualisasi simbolik, yaitu visualisasi tema yang tidak digambar secara langsung dari obyeknya melainkan melaui perwakilan dari simbol-simbol visual yang sudah konvensi universal

Desain batik dapat dikembangkan dari karakter dan selera segmentasi konsumen. Beberapa segmen konsumen yang secara volume sangat besar sehingga sangat potensial untuk dikembangkan menjadi trendsetter, yaitu desain batik untuk segmen remaja, anak-anak dan bayi, serta desain batik berkarakter maskulin. Desain batik yang dapat dikembangkan dari selera desain yang tidak menginginkan representasi desain yang rumit dan ramai, melainkan desain yang halus dan cenderung sederhana agar mudah disesuaikan dengan padanan pakaian dan asesoris lain disebut juga Desain Batik Minimalis

Quality Function Deployment (QFD) adalah suatu sistem untuk mengubah keinginan pelanggan menjadi karakteristik kualitas dan mengembangkan suatu desain kualitas untuk menghasilkan produk yang secara sistematis menyebarkan (deploying) hubungan antara keinginan dan karakteristik tersebut. (Akao, 1990)

Dalam penelitian tentang "Kajian Karakteristik Desain Batik Cap Berorientasi Selera Konsumen Sebagai Upaya Pemberdayaan UKM Produsen Batik Cap Di Wilayah Jetis Sidoarjo" oleh Irma Russanti, Metode Quality Function Deployment (QFD) digunakan untuk pengembangan produk batik cap yang berorientasi pada selera konsumen. Kesimpulan penelitian ini yaitu Karakteristik desain batik cap yang berorientasi pada selera konsumen adalah meliputi ragam hias ditinjau dari bentuknya mengacu pada motif-motif yang telah ada yang menjadi kekhasan pengrajin batik dan tren, untuk menghindari kejenuhan konsumen maka desainer harus selalu melakukan inovasi baik dalam sumber ide dan kreatifitas bentuknya. Untuk ukuran,adanya keseimbang antara motif utama, penunjang serta isenisennya dan pinggiran. Untuk peletakan ragam hias dapat diletakkan dimana saja asal tidak terlalu monoton karena menyebabkan kebosanan. Untuk warna pada ragam hias adalah warna-warna primer maupun sekunder dengan perpaduan komposisi warna yang cenderung analog.

Metode $Q F D$ juga diterapkan dalam penelitian "Penerapan Metode Quality Function Deployment untuk Meningkatkan Produk Kain Batik Tulis yang Berkualitas di Desa Cibelok Kecamatan Taman Kabupaten Pemalang" (Luthfianto, 2010). Dalam penelitian tersebut terdapat sebelas atribut yang dipentingkan oleh konsumen, yaitu bahan baku utama kuat dan tahan lama, tidak luntur, halus, nyaman dipakai, corak menarik dan rapi, banyak pilihan warna, mempunyai ciri khas, mudah perawatannya, motif modern dan klasik, lentur (fleksibel) dan murah harganya

\section{Metode Penelitian}

Penelitian ini dilakukan dalam upaya pengembangan desain motif batik khas Kalimantan Timur sesuai dengan selera pasar. Metode yang digunakan pada penelitian ini adalah metode Quality Function Deployment (QFD) untuk pengembangan desain motif batik khas Kalimantan Timur. Objek yang diteliti adalah batik khas Kalimantan Timur. Dengan menganalisis motif batik khas Kalimantan Timur yang sesuai dengan keinginan pasar guna pengembangan produk. 
Data untuk penelitian ini diperoleh dari hasil survey terhadap 100 orang konsumen. Dari hasil survey tersebut diharapkan diperoleh masukan dari konsumen tentang keinginan mereka. User yang dijadikan responden meliputi beberapa wilayah Provinsi Kalimantan Timur, khususnya Kota Samarinda. Implementasi QFD dalam pengembangan desain motif batik khas Kalimantan Timur dan aplikasinya secara umum dibagi dalam tiga tahap, yaitu :

1. Tahap pengumpulan Voice of Customer.

Pada tahap ini dilakukan survey untuk memperoleh suara pelanggan. Proses QFD membutuhkan data konsumen yang ditulis sebagai atribut-atribut dari produk. Atribut-atribut atau kebutuhan-kebutuhan ini merupakan keuntungan potensial yang dapat diterima konsumen dari produk.

2. Tahap penyusunan House of Quality

Langkah-langkah dalam menyusun rumah kualitas (House of Quality), secara ringkas adalah sebagai berikut :

- Tahap I Matrik kebutuhan konsumen

- Tahap II Matrik perencanaan, bertujuan untuk mengukur kebutuhan-kebutuhan konsumen dan menetapkan tujuan-tujuan performansi kepuasan.

- Tahap III Respon teknik,yaitu transformasi dari kebutuhan-kebutuhan konsumen yang bersifat non teknis menjadi data yang bersifat teknis guna memenuhi kebutuhankebutuhan tersebut.

- Tahap IV Menentukan hubungan respon teknis dengan kebutuhan konsumen.

- Tahap V Korelasi teknis, memetakan hubungan dan kepentingan atau respon teknis.

- Tahap IV Benchmarking dan penetapan target

3. Tahan analisis dan interpretasi

merupakan tahap teknis dan implementasi Quality

Function Deployment. Di sini dilakukan analisis dan interpretasi terhadap rumah kualitas yang sudah disusun pada tahap sebelumnya. Dan bila dilanjutkan pada pembuatan suatu produk maka akan dapat dihasilkan produk yang mempunyai karakteristik yang kuat dalam memenuhi keinginan konsumen.

\section{Hasil Dan Pembahasan}

\section{Penyusunan Atribut Kepentingan}

Kuesioner pendahuluan disebar sebagai langkah awal penelitian, kepada pihak-pihak yang berhubungan dengan desain motif batik seperta pegawai-pegawai instansi pemerintah, pelajar dan mahasiswa, guru/dosen, dan masyarakat umum. Hasil dari kuesioner pendahuluan tersebut, didapat datadata untuk menentukan atribut yang dianggap penting dalam pengembangan desain motif batik khas Kaltim. Atribut-atribut tersebut adalah:
1) Motif batik menarik

2) Bentuk motif batik mempunyai ciri khas Kaltim

3) Perpaduan motif batik asli Kaltim dan modern

4) Ukuran motif sedang dan kecil

5) Bentuk motif flora (sulur-sulur)

6) Motif tidak terlalu ramai

7) Perpaduan warna motif senada dan serasi Selanjutnya, atribut-atribut tersebut dicari tingkat kepentingannya dengan menyebarkan kuesioner utama kepada 100 orang responden.

\section{Uji Validitas Dan Reliabilitas}

Pengukuran reliabilitas kuisioner untuk melihat apakah kuisioner yang akan digunakan cukup andal atau tidak sehingga layak untuk dijadikan kuisioner penelitian. Pengukuran reliabilitas kuisioner ini menggunakan metode Alpa Cronbach dengan bantuan Software SPSS. Uji validitas digunakan untuk mengetahui apakah atribut kuesioner tersebut mampu menggambarkan apa yang diinginkan konsumen.

Tabel 1. Hasil uji reliabilitas kuisioner

\begin{tabular}{cc}
\hline Cronbach's alpha & N of Items \\
\hline .631 & 7 \\
\hline
\end{tabular}

Tabel 2. Hasil uji validitas kuesioner

\begin{tabular}{clcc}
\hline $\mathbf{N}$ & \multicolumn{1}{c}{ Atribut } & $\begin{array}{c}\text { Nilai } \\
\mathbf{~}\end{array}$ & Valid \\
\hline 1 & $\begin{array}{l}\text { Motif batik menarik } \\
\text { Bentuk motif batik }\end{array}$ & 0,214 & Valid \\
2 & $\begin{array}{l}\text { mempunyai ciri khas Kaltim } \\
\text { memplid }\end{array}$ & Valid \\
3 & $\begin{array}{l}\text { Perpaduan motif batik asli } \\
\text { Kaltim dan modern }\end{array}$ & 0,235 & Valid \\
4 & $\begin{array}{l}\text { Ukuran motif sedang dan } \\
\text { kecil }\end{array}$ & 0,485 & Valid \\
5 & $\begin{array}{l}\text { Bentuk motif flora (sulur- } \\
\text { sulur) }\end{array}$ & 0,356 & Valid \\
6 & $\begin{array}{l}\text { Motif tidak terlalu ramai } \\
\text { Perpaduan warna motif }\end{array}$ & 0,409 & Valid \\
senada dan serasi & 0,421 & Valid \\
\hline
\end{tabular}

Dari hasil perhitungan diperoleh nilai Alpha untuk tingkat kepentingan 0,631 Dengan demikian dapat dinyatakan bahwa kuesioner penelitian andal dan layak untuk digunakan dalam penelitian ini. Dari tabel di atas terlihat seluruh atribut kebutuhan pelanggan valid karena mempunyai nilai lebih dari $r$ kritis 0,195 .

\section{Matrik Perancangan}

Matriks perencanaan bertujuan untuk menentukan atribut mana yang akan dikembangkan terlebih dahulu. Dari hasil kuesioner utama didapat hal-hal yang dipentingkan oleh pelanggan terhadap desain motif batik khas Kaltim yang terlihat pada tabel berikut. 
Tabel 3. Customer Importance

\begin{tabular}{clc}
\hline No & \multicolumn{1}{c}{ Atribut } & $\begin{array}{c}\text { Customer } \\
\text { importance }\end{array}$ \\
\hline 1 & Motif batik menarik & 4,77 \\
2 & $\begin{array}{l}\text { Bentuk motif batik } \\
\text { mempunyai ciri khas Kaltim }\end{array}$ & 4,70 \\
3 & $\begin{array}{l}\text { Perpaduan warna motif } \\
\text { senada dan serasi }\end{array}$ & 4,37 \\
4 & $\begin{array}{l}\text { Perpaduan motf batik asli } \\
\text { Kaltim dan modern }\end{array}$ & 4,05 \\
5 & $\begin{array}{l}\text { Motif tidak terlalu ramai } \\
6\end{array}$ & $\begin{array}{l}\text { Bentuk motif flora (sulur- } \\
\text { sulur) }\end{array}$ \\
7 & $\begin{array}{l}\text { Ukuran motif sedang dan } \\
\text { kecil }\end{array}$ & 3,42 \\
\hline
\end{tabular}

Dari tabel terlihat bahwa motif batik menarik merupakan atribut yang paling penting bagi konsumen dalam memilih desain motif batik khas Kaltim. Sedangkan ukuran motif sedang dan kecil merupakan atribut dengan nilai kepentingan yang paling rendah.

\section{Penyusunan Respon Teknis}

Respon teknis yang didapatkan menggambarkan kemampuan teknis yang mampu merespon keinginan pelanggan seperti pada tabel 4 .

Selanjutnya dibuat matriks korelasi teknis, untuk mengetahui hubungan yang terjadi antara persyaratan pelanggan dengan respon teknis. Untuk meningkatkan derajat hubungan antara persyaratan pelanggan dengan respon teknis, digunakan simbol sebagai tabel 5.

Tabel 4. Respon Teknis

\begin{tabular}{|c|c|c|c|}
\hline No & Respon teknis & \multicolumn{2}{|c|}{ Spesifikasi } \\
\hline 1 & Pemilihan warna & \multicolumn{2}{|c|}{$\begin{array}{l}\text { Pemilihan warna dan perpaduannya harus tepat } \\
\text { sehingga memberi kesan indah, serasi dan harmo } \\
\text { Warna-warna cerah merupakan warna khas suku } \\
\text { Kaltim. }\end{array}$} \\
\hline 2 & $\begin{array}{l}\text { Keseimbangan } \\
\text { motif }\end{array}$ & \multicolumn{2}{|c|}{$\begin{array}{l}\text { Motif harus mempunyai kesamaan antara kekuat } \\
\text { yang saling berhadapan dan menimbulkan adany } \\
\text { kesan seimbang secara visual. }\end{array}$} \\
\hline 3 & Proporsi & \multicolumn{2}{|c|}{$\begin{array}{l}\text { Kesesuaian ukuran antara kondisi luas atau } \\
\text { sempitnya ruang gambar dengan besar kecilnya } \\
\text { motif. }\end{array}$} \\
\hline 4 & Komposisi & \multicolumn{2}{|c|}{$\begin{array}{l}\text { Kesesuaian susunan dari berbagai ukuran, maca } \\
\text { bentuk dasar motif sehingga tercipta bentuk dan } \\
\text { motif yang tertata serasi, indah dan berseni. }\end{array}$} \\
\hline \multirow[t]{7}{*}{5} & Ragam hias & $\begin{array}{l}\text { Bentuk dasar hiasan } \\
\text { Ragam hias harus ber } \\
\text { Kaltim untuk mempe } \\
\text { bangsa. }\end{array}$ & $\begin{array}{l}\text { i pola berulang } \\
\text { tumbuhan kha } \\
\text { as kultural suk }\end{array}$ \\
\hline & \multicolumn{3}{|c|}{ Tabe 5. Simbol Korelasi } \\
\hline & Simbol & Keterangan & Bobot \\
\hline & $<$ kosong $>$ & Tidak ada hubungan & 0 \\
\hline & - & Hubungan kuat & 9 \\
\hline & $\bullet$ & Hubungan sedang & 3 \\
\hline & $\Delta$ & Hubungan lemah & 1 \\
\hline
\end{tabular}


Tabel 6. Korelasi Teknis

\begin{tabular}{|c|c|c|c|c|c|}
\hline$x$ & 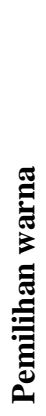 &  & 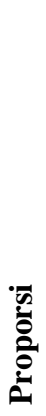 & 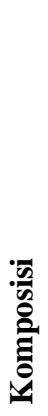 & 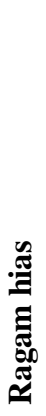 \\
\hline Motif batik menarik & $\Delta$ & $\Delta$ & $\Delta$ & $\Delta$ & $\mathbf{\square}$ \\
\hline $\begin{array}{l}\text { Bentuk motif batik mempunyai ciri khas } \\
\text { Kaltim }\end{array}$ & $\mathbf{\square}$ & $\Delta$ & $\Delta$ & $\Delta$ & $\mathbf{\square}$ \\
\hline Perpaduan warna motif senada dan serasi & $\mathbf{\square}$ & $\mathbf{\square}$ & $\mathbf{\square}$ & $\mathbf{\square}$ & $\bullet$ \\
\hline $\begin{array}{l}\text { Perpaduan motif batik asli Kaltim dan } \\
\text { modern }\end{array}$ & $\mathbf{\square}$ & $\Delta$ & $\Delta$ & $\Delta$ & $\mathbf{\square}$ \\
\hline Motif tidak terlalu ramai & $\Delta$ & $\mathbf{\square}$ & • & $\mathbf{\square}$ & $\Delta$ \\
\hline Bentuk motif flora (sulur-sulur) & $\Delta$ & $\Delta$ & $\Delta$ & $\Delta$ & 口 \\
\hline Ukuran motif sedang dan kecil & $\Delta$ & $\mathbf{\square}$ & $\mathbf{\square}$ & $\mathbf{\square}$ & $\bullet$ \\
\hline
\end{tabular}

Tabel 7. Penentuan target dan Pembobotan

\begin{tabular}{lccccc}
\hline \multicolumn{1}{c}{ Atribut } & $\begin{array}{c}\text { Target } \\
\text { value }\end{array}$ & $\begin{array}{c}\text { Existing } \\
\text { value }\end{array}$ & $\begin{array}{c}\text { Customer } \\
\text { importance }\end{array}$ & Weight & $\begin{array}{c}\text { Weight } \\
\text { (\%) }\end{array}$ \\
\hline Motif batik menarik & 5 & 3 & 4,77 & 7,95 & 16,73 \\
$\begin{array}{l}\text { Bentuk motif batik mempunyai ciri } \\
\text { khas Kaltim }\end{array}$ & 5 & 3 & 4,70 & 7,83 & 16,48 \\
$\begin{array}{l}\text { Perpaduan warna motif senada dan } \\
\text { serasi }\end{array}$ & 5 & 2 & 4,37 & 10,93 & 22,99 \\
$\begin{array}{l}\text { Perpaduan motif batik asli Kaltim } \\
\text { dan modern }\end{array}$ & 4 & 2 & 4,05 & & \\
Motif tidak terlalu ramai & 4 & 3 & 3,42 & & 17,05 \\
Bentuk motif flora (sulur-sulur) & 3 & 2 & 3,40 & 5,56 & 9,60 \\
Ukuran motif sedang dan kecil & 3 & 3 & 3,05 & 3,05 & 10,73 \\
& & & & 47,52 & 100 \\
\hline
\end{tabular}

Matrik korelasi ini menunjukkan hubungan antara persyaratan pelanggan dengan respon teknis (persyaratan teknis) untuk pengembangan desain motif batik khas Kaltim.

\section{Penyusunan House of Quality (Hoq)}

$H o Q$ adalah matriks berbentuk rumah yang menghubungkan keinginan dari pelanggan (what) dan bagaimana suatu produk akan didesain dan diproduksi agar memenuhi keinginan pelanggan (how). Matriks $H o Q$ ini dapat digunakan dalam perencanaan pengembangan desain motif batik khas Kaltim. HoQ untuk pengembangan desain motif batik terlihat pada diagram di bawah ini: 


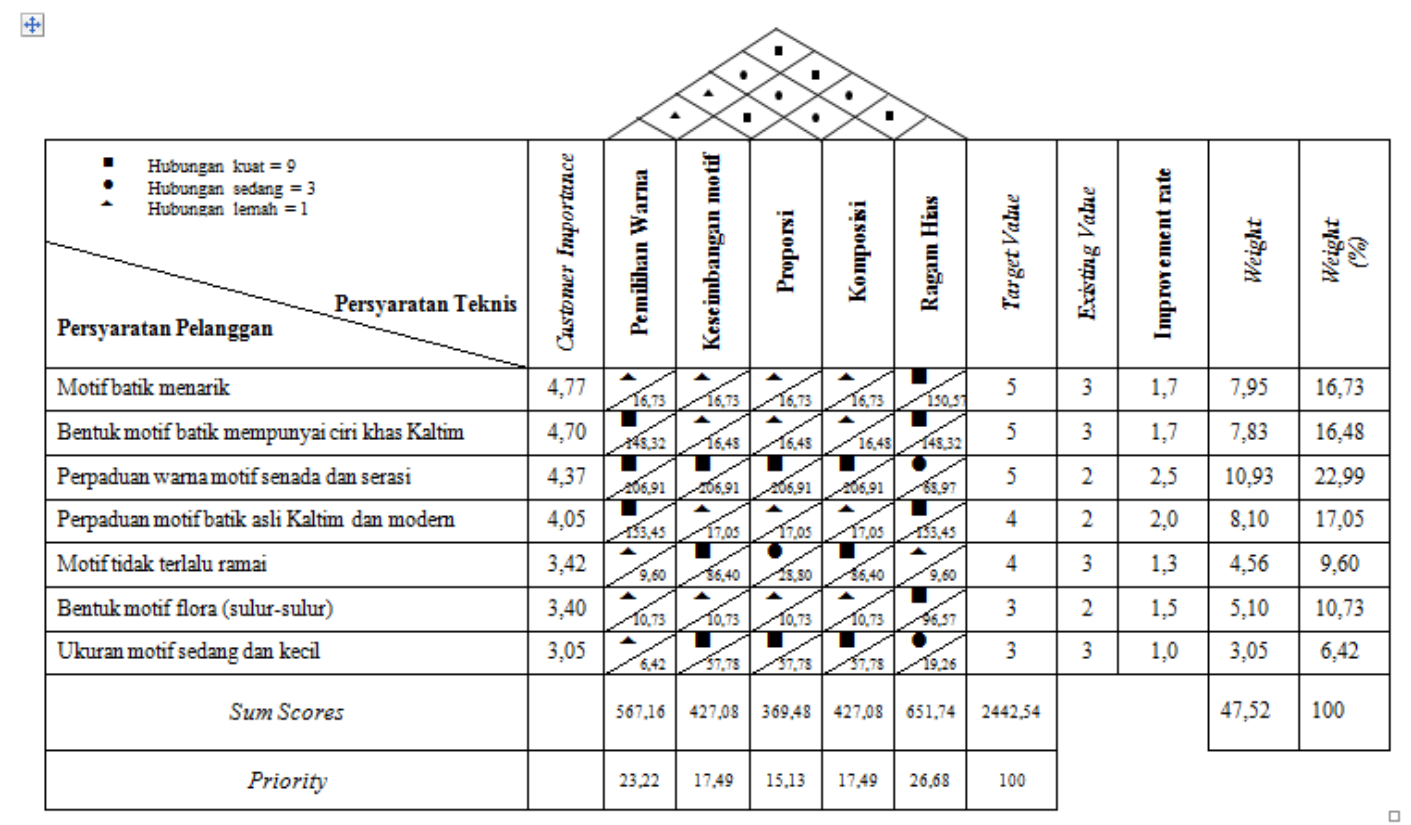

Gambar 1. House of Quality (HoQ)

\section{Kesimpulan}

Berdasarkan hasil penelitian, dapat ditarik kesimpulan yaitu dapat ditentukan atribut-atribut desain motif batik khas Kaltim yaitu: motif batik menarik, bentuk motif batik mempunyai ciri khas Kaltim, perpaduan warna motif senada dan serasi, perpaduan motif batik asli Kaltim dan modern, motif tidak terlalu ramai, bentuk motif flora (sulur-sulur) dan ukuran motif sedang dan kecil. Nilai atribut tertinggi untuk tingkat kepentingan adalah motif batik menarik, dengan nilai rata-rata 4,77. Dan untuk atribut kepentingan terendah adalah ukuran motif sedang dan kecil dengan nilai 3,05

Respon teknis untuk pengembangan desain motif batik khas Kaltim adalah pemilihan warna, keseimbangan motif, proporsi, komposisi.

Pengembangan desain motif batik mengacu pada unsur-unsur berkaitan dengan ragam hias khas suku asli Kalimantan Timur yang dipadukan dengan unsur-unsur modern.

\section{Daftar Pustaka}

Akao, Y. 1990. QFD : Integratisng Costumer Requirement into Product Design. Productifity Press, Cambridge. Massachusetts.

Ayudea, Fani et al. 2009. Melestarikan Budaya Batik dan Keris. http://www.suaramerdeka.com (26 mei 2011).
Dewan Bahasa dan Pustaka. 2001. Dewan Sastra. DBP. Jakarta.

Djatmiko, K. A. 2009. Seni Batik Diakui Dunia. http://www.pikiranrakjat.com (26 Mei 2011).

Fuadi, Dedi et al. $2009 . \quad$ Batik. http://pesonabatik.site40.net/index.html $\quad$ (26 Mei 2011).

Harsokoesoemo, D. 2004. Pengantar Perancangan Teknik (Perancangan Produk) edisi kedua. Penerbit ITB. Bandung.

Indrojarwo, Baroto Tavip. Development of Indonesia New Batik Design by Exploration and Exploitation of Recent Context. Institut Teknologi Sepuluh November.

Kerlogue, F. G. 2004. Batik : Design, Style \& History. London : Thames \& Hudson.

Russanti, Irma. Kajian Karekteristik Desain Batik Cap Berorientasi Selera Konsumen Sebagai Upaya pemberdayaan UKM produsen Batik Cap di Wilayah Jetis Sidoarjo. http://lontar.ui.ac.id/opac/themes/libri2/detail.j sp?id=134029\&lokasi=lokal

Luthfianto, S \& Suwandono. 2010. "Penerapan Metode Quality Function Deployment Untuk Meningkatkan Produk Kain Batik Tulis Yang Berkualitas Di Desa Cibelok Kecamatan Taman 